\title{
Cost and Benefit Analysis of Supplier Risk Mitigation in an Aerospace Supply Chain
}

\author{
(presented at the 6th IESM Conference, October 2015, Seville, Spain) $\odot \mathrm{I}^{4} \mathrm{e}^{2} 2015$
}

\author{
Abroon Qazi ${ }^{1}$, John Quigley ${ }^{1}$, Alex Dickson ${ }^{1}$, Barbara Gaudenzi ${ }^{2}$ and Şule Önsel Ekici ${ }^{3}$ \\ ${ }^{1}$ Strathclyde Business School, University of Strathclyde, G4 0QU Glasgow, UK \\ (abroon.qazi, j.quigley, alex.dickson)@strath.ac.uk \\ ${ }^{2}$ Faculty of Economics, University of Verona, Verona, Italy \\ barbara.gaudenzi@univr.it \\ ${ }^{3}$ Industrial Engineering Department, Dogus University, Istanbul, Turkey \\ sonsel@dogus.edu.tr
}

\begin{abstract}
Risk identification and risk estimation are important stages of any risk management process. Existing research in Supply chain risk management has mainly focused on these two stages whereas risk evaluation has not been fully explored which is an equally significant stage involving evaluation of different risk mitigation strategies. The main purpose of this paper is to propose a method of evaluating different mitigation strategies through cost and benefit analysis. The proposed method introduces a unique concept of integrating cost and relative impact of different combinations of mitigation strategies within a network setting of interconnected risk triggers, risk factors and risk mitigation strategies. We have applied our method on a case study that was conducted in an aerospace supply chain. Our approach is useful in identifying an optimal combination of mitigation strategies against a given budget constraint. Furthermore, the model can also be used for determining such strategies in relation to a given level of risk exposure. We have incorporated NoisyOR function within the Bayesian Network model in order to reduce the complexity involved in eliciting a huge number of conditional probability values.
\end{abstract}

Keywords-Supply chain risk management; risk evaluation; risk mitigation strategies; NoisyOR function

\section{INTRODUCTION}

Risk management is an established field in some areas of organizational life like finance but it is still a developing theme within the realm of supply chain management [1]. There is a consensus among researchers on treating risk management as a process comprising three stages of risk identification, risk estimation and risk evaluation [2].

Supply Chain Risk Management (SCRM) is defined as "the management of supply chain risks through coordination or collaboration among the supply chain partners so as to ensure profitability and continuity" [3]. Supply chain risks can be viewed with respect to three broad perspectives; a 'butterfly' concept that segregates the causes, risk events and the ultimate impact, the categorization of risks with respect to the resulting impact in terms of delays and disruptions and network based classification in terms of local-and-global causes and local-andglobal effects [4].
It is important to realize that risk exists at various levels, inside the focal company and at the network level. Furthermore, risk evaluation depends on the stakeholder's perspective and therefore, the subjective judgement of a particular stakeholder determines what constitutes a risk and what level of risk is acceptable [5].

Bayesian Belief Network (BBN) is a probabilistic graphical model that represents causal relationship between variables and captures uncertainty in dependency in terms of conditional probabilities $[6,7]$. BBNs have been used in modelling supply chain risks and found to be an effective technique, however, the scope of such models has been limited to focused areas like supplier selection, risk profiling, etc. [8-10]. We make use of the BBNs in capturing interdependency between supply chain risks and modelling the interaction of mitigation strategies with associated risks taking into account the relative cost and benefit of such strategies. As the number of conditional probability values grows exponentially with the increase in number of causal factors for a risk, we utilize the concept of NoisyOR function in order to reduce the number of values from exponential to linear.

\section{Research Problem and Contribution}

Existing research in SCRM has mainly focused on the first two stages of risk management process; risk identification and risk estimation. In general, risk mitigation strategies have been described qualitatively and no study has investigated evaluation of risk mitigation strategies within a network setting of interconnected risks, triggers, consequences and mitigation strategies on the basis of cost and benefit analysis. This research paper is a first step towards bridging this major research gap. It attempts to propose a method that can help researchers and practitioners appreciate the importance of risk evaluation and develop better models for managing supply chain risks.

\section{Outline}

Literature review is briefly presented in Section II. BBNs and NoisyOR function are described in Section III. Section IV describes our proposed method of evaluating control strategies followed by its demonstration as a Case Study in Section V. Results and managerial implications are discussed in Section 
VI followed by the conclusion and future research presented in Section VII.

\section{LITERATURE REVIEW}

Risk has been defined as a chance of danger, damage, loss, injury or any other undesired consequences [11]. According to Knight [12], risk is something measurable in a way that probabilities of the outcomes can be estimated whereas, uncertainty is not quantifiable and probabilities of the possible outcomes are not known. According to Jüttner et al. [13], "SCRM aims to identify the potential sources of supply chain risks and implement appropriate actions to avoid or contain supply chain vulnerability". Vulnerability is defined as an exposure to serious disturbances from risks within the Supply Chain as well as risks external to the Supply Chain [14].

Simulation has been extensively used by researchers in modelling supply chain risks. Simulation techniques used in the realm of SCRM include agent-based modelling [15], Monte Carlo simulation [16, 17], discrete event simulation [18], system dynamics modelling [19] and Petri-Net simulation [20]. Generally, the existing studies have either focused on addressing a specific problem or considered risks as independent factors. Risk mitigation strategies have not been evaluated within the network of interconnected risks and strategies and therefore, existing models fail to capture a holistic account of all three stages of risk management process incorporating interdependence between all factors.

Many researchers have proposed proactive mitigation strategies while limited studies have focused on reactive strategies [21-24]. Wieland [25] developed mathematical models for determining optimal solution and break-even points in the realm of four strategies-agility, robustness, resilience and rigidity. Multi-criteria decision making [26, 27] and stochastic programming [28-31] have also been utilized for assessing supply chain risks.

According to Johnson [32], capacity risks can be reduced by outsourcing and building a flexible web of partners whereas, operational hedging can help in reducing currency and political risks. Christopher and Lee [3] proposed strategies of information accuracy, visibility, accessibility and responsive corrective actions. Zsidisin et al. [33] recommended implementation of supplier improvement programs and mitigation of supply disruptions through creating business interruption plans, developing demand forecasts and modelling supply processes. Blackhurst et al. [34] emphasized the significance of real-time sharing of correct information from every node in the supply chain and predicting capacity bottlenecks in global transportation networks. According to Kleindorfer and Saad [35], approaches used to mitigate disruption risks must fit the characteristics and needs of the underlying environment of the focal supply chain.

Sinha et al. [36] introduced a comprehensive risk management process for mitigating supplier risks in an aerospace supply chain. Their method links risk triggers to corresponding risk factors and helps in identifying risk mitigation strategies, however, they did not consider the cost and benefit associated with implementing these strategies. Tummala and Schoenherr [37] introduced a Supply Chain Risk
Management Process (SCRMP) and proposed allocating resources to the important risk factors. They assigned cumulative score to each risk factor on the basis of its probability, impact and risk control cost. However, they did not consider the uncertainty involved in risk mitigation. Furthermore, they did not capture the interdependent nature of strategies, risk triggers and risk factors.

\section{BAYESIAN BELIEF NETWORKS}

$\mathrm{BBN}$ is an acyclic directed graphical model comprising nodes representing uncertain variables and arcs indicating causal relationships between variables whereas the strength of dependency is represented by the conditional probability values [6]. BBNs have started gaining the interest of researchers in modelling supply chain risks [38]. BBNs offer a unique feature of modelling risks combining both the statistical data and subjective judgment in case of non-availability of data [39, 40]. Researchers have used the BBNs to model specific domains of supply chain risks and validated these models through case studies. The existing BBN based models in SCRM have mainly focused on evaluating risks on the basis of probabilistic interdependency exclusively; however, it is equally important to consider the loss values corresponding to different risks and the cost and benefit associated with each mitigation strategy and to include all these factors into the model itself. We aim to utilize the efficacy of BBNs in dealing with uncertainties and modelling all three stages of SCRM process.

The number of conditional probability values increases exponentially with the increase in number of parent nodes leading to complexity involved in eliciting these probabilities, therefore, it is important to consider incorporating assumptions in the model in order to cope with this problem. NoisyOR function is a useful tool that simplifies the problem and necessitates eliciting only $n+1$ parameters where $n$ represents the number of parent nodes of a child node [41].

\section{NoisyOR Function}

Let $C_{1}, C_{2}, \ldots, C_{n}$ be binary variables indicating all the causes of a binary risk variable $R$. Each event $C_{i}=$ True causes $R=$ True unless an inhibitor prevents it with probability of $q_{i}$ [42].

$$
P\left(R=\text { False } \mid C_{i}=\text { True }\right)=q_{i}
$$

Assuming all inhibitors as independent,

$$
P\left(R=\text { False } \mid C_{1}, C_{2}, \ldots, C_{n}\right)=\prod_{j \in T} q_{j}
$$

where $\mathrm{T}$ is the set of indices for variables in the state 'True'.

If $P\left(R=\right.$ True $\mid C_{1}=\cdots=C_{n}=$ False $)>0$, then leak factor can be incorporated into the model representing a background event that is always on.

\section{PRoposed METHOD}

Our proposed method is a first step towards integrating the three stages of SCRM process within the modelling framework of BBNs. We do not follow the process flow of a supply chain as it might not be feasible to model a huge network. The method comprises three main stages of problem structuring, instantiation and inference as shown in Fig. 1. 


\section{Problem Structuring}

This stage comprises important steps of identifying key supply chain risks, associated risk triggers and mitigation strategies, developing the network structure and expressing nodes as statistical variables. The problem owner needs to ensure that the model is developed to represent the real problem. Furthermore, the model builder can assist in structuring the model keeping in view the mechanics of a BBN.

\section{Instantiation}

This stage involves evaluation of (conditional) probabilities either through elicitation from the experts or extraction from the data. Probability elicitation is the most difficult task of the modelling process as the experts find it challenging to describe the conditional probabilities. As the values grow exponentially with the increase in number of parents of a child node, therefore, we introduce the NoisyOR function in order to reduce the number of such values from exponential to linear. In this stage, the loss corresponding to each risk trigger is also ascertained followed by the evaluation of cost associated with different mitigation strategies.

\section{Inference}

In this stage, key risk triggers are identified after propagating conditional probability and loss values across the interconnected risk factors, triggers and mitigation strategies. The values from the network are exported to Microsoft Excel for conducting cost and benefit analysis of various combinations of mitigation strategies. Depending on the risk tolerance of the stakeholder, appropriate strategies are selected for implementation.

\section{CAse Study}

We apply our proposed method on a case study presented by Sinha et al. [36]. They had applied their methodology on an aerospace supplier specializing in machined parts. After identifying key risk factors for the supplier and using the failure modes and effects analysis (FMEA), they were able to determine potential failure modes and recommend corrective actions. We have transformed their FMEA representation into risk factors, triggers and mitigation strategies as shown in Table I. Conditional probability values for risk triggers and risk factors are shown in Appendix A whereas loss values for risk triggers and costs associated with different mitigation strategies are presented in Appendices B and $\mathrm{C}$ respectively. In contrast to the use of ordinal scales for occurrence and severity in FMEA, we make use of the probability and loss values in our model. Therefore, we have mapped the values for occurrence and severity used in the case study [36] to the parameters of probability and loss respectively. Furthermore, as the case study [36] had not considered the uncertainty associated with the interaction between risk triggers and risks, we have assumed the values for quantification of the NoisyOR function.

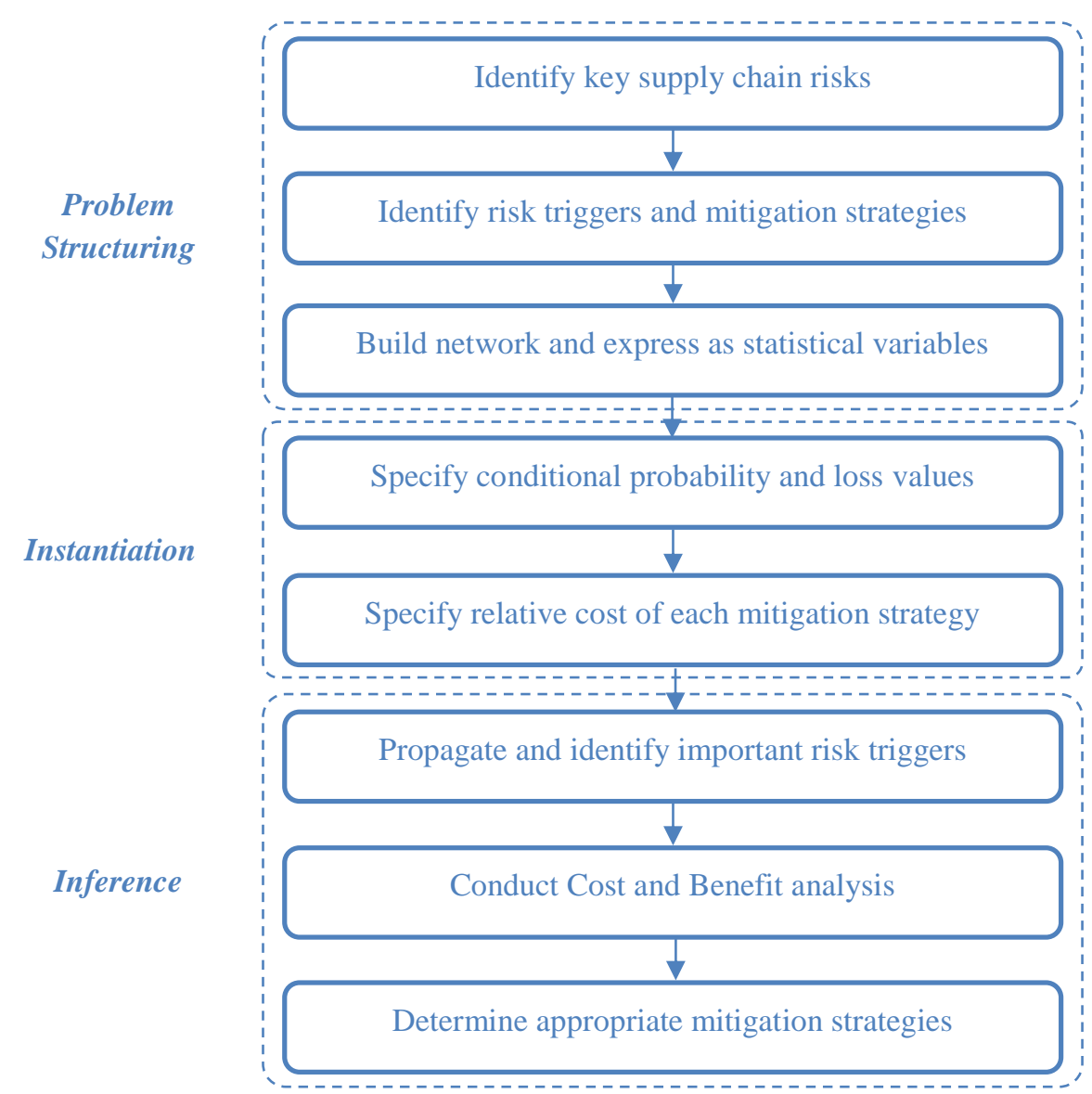

Fig. 1. Cost and benefit based method of evaluating risk mitigation strategies. 
TABLE I. RISK FACTORS, Risk TRIGGERS AND MitigATION STRATEGIES (ADAPTED FROM [36])

\begin{tabular}{cll}
\hline \multicolumn{1}{c}{ Risk Factor } & Risk Trigger & Mitigation Strategy \\
\hline & Machine breakdown (T1) & Effective maintenance (M1) \\
& Non-availability of raw material (T2) & Visibility of demand to vendor (M2) \\
& Labour problems (T3) & Training (M4) \\
& Improperly trained workers (T4) & Communication tools (M5) \\
& Natural calamity at vendor's place (T5) & Selecting the right quality material (M6) \\
& Failure to communicate (T6) & Supplier assessment (M7) \\
& Low quality material used at vendor's facilities (T7) & Using correct quality programs (M8) \\
Poor quality of incoming material (R2) & Improper process at the vendor's end (T8) & Training (M4) \\
& Insufficient use of quality tools (T9) & Mass customization (M9) \\
& Improperly trained workers (T4) & Good contact with customer (M10) \\
& No clear market perception (T10) & Implementing the best technology (M11) \\
& Poor after-service network (T11) & As per prevailing market conditions (M12) \\
\hline
\end{tabular}

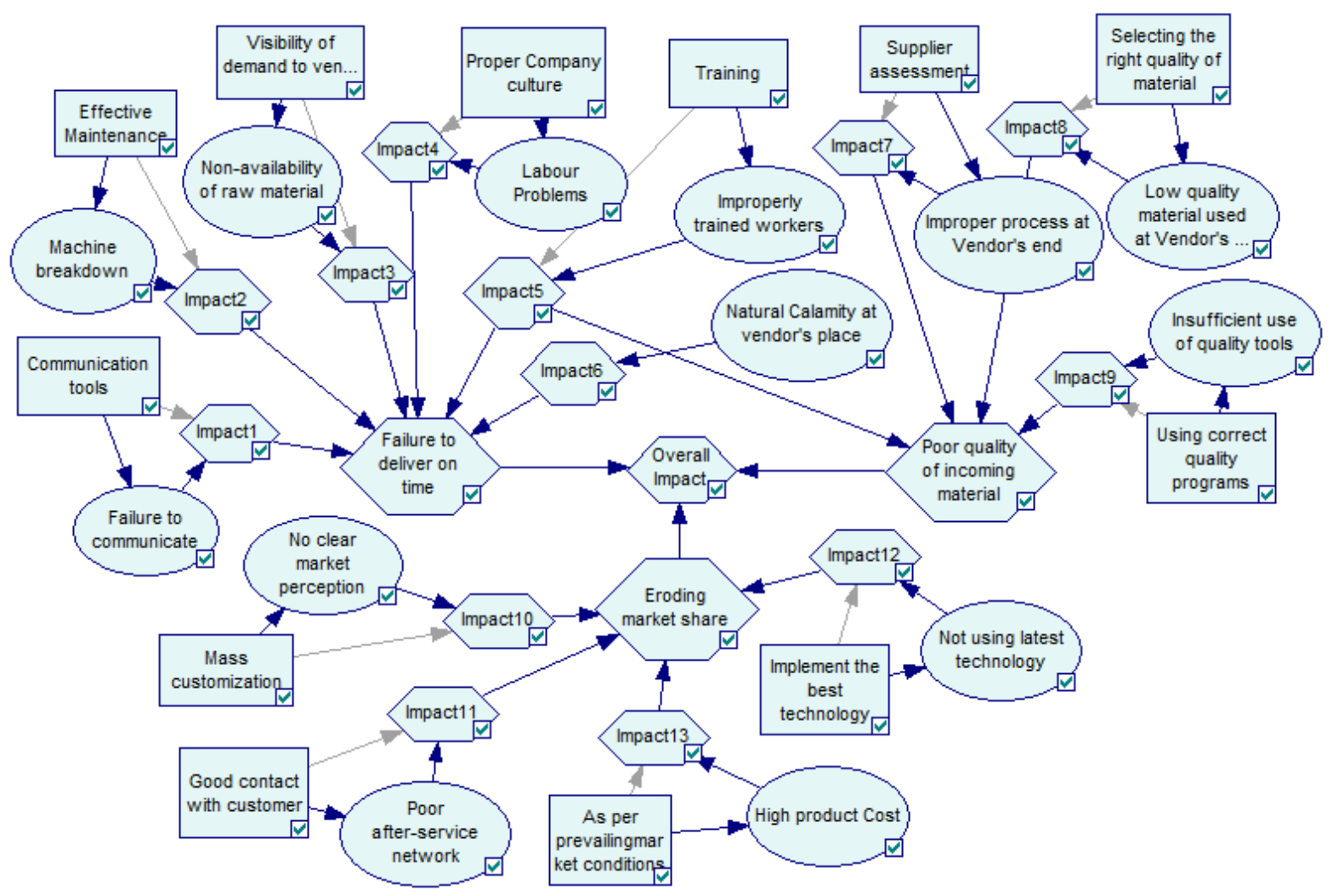

Fig. 2. Risk factors, risk triggers and mitigation strategies modelled as a BBN.

BBN based model was developed in GeNIe [43] as shown in Fig. 2. Each mitigation strategy appears as a rectangular node having binary states of 'Yes (Y)' and 'No (N)'. Each risk factor/trigger is represented by an oval node having binary states of 'True (T)' and 'False (F)'. Risk exposure of each trigger is represented by a diamond node. Risk exposure values of all the triggers corresponding to each risk factor are aggregated through NosiyOR function and finally, the overall risk exposure is calculated through aggregating risk exposure values across all three risk factors.

\section{RESULTS AND DISCUSSION}

Once the Bayesian network was updated, risk exposure values for the risk triggers were evaluated as shown in Table II. 'No clear market perception' proved to be the most significant risk trigger and keeping in view the low probability and loss values associated with 'Natural calamity at vendor's place', its risk exposure was insignificant. 'Machine breakdown' was also an important trigger having a high value of risk exposure. 
Array of loss exposure values corresponding to different combinations of mitigation strategies was exported to Microsoft Excel. Furthermore, another array of costs associated with these strategies was generated in GeNIe and subsequently exported to Microsoft Excel. The resulting graph representing cost and benefit analysis of different combinations of mitigation strategies is shown in Fig. 3. Data points displayed in blue colour represent the variation in risk exposure with that of the cost associated with different strategies. It is important to note that there is a substantial decrease in risk exposure with slight increase in mitigation cost, however, the rate of this decrement reduces with an increase in mitigation cost. Data points displayed in red colour indicate the improvement in risk exposure incorporating the cost of implementing strategies. All such data points having non-negative values can be considered as appropriate combinations of strategies from the perspective of a risk-neutral decision maker because we have considered expected values in our model.

\section{TABLE II. RISK EXPOSURE VALUES FOR RISK TRIGGERS}

\begin{tabular}{ll}
\hline Risk Trigger & Risk Exposure \\
\hline Machine breakdown & 51.98 \\
Non-availability of raw material & 9.9 \\
Labour problems & 0.44 \\
Improperly trained workers & 18.7 \\
Natural calamity at vendor's place & 0.01 \\
Failure to communicate & 24.75 \\
Low quality material used at vendor's facilities & 5.45 \\
Improper process at the vendor's end & 31.35 \\
Insufficient use of quality tools & 16.5 \\
Improperly trained workers & 18.7 \\
No clear market perception & 97.01 \\
Poor after-service network & 21.24 \\
Not using the latest technology & 46.2 \\
High product cost & 13.2 \\
\hline
\end{tabular}

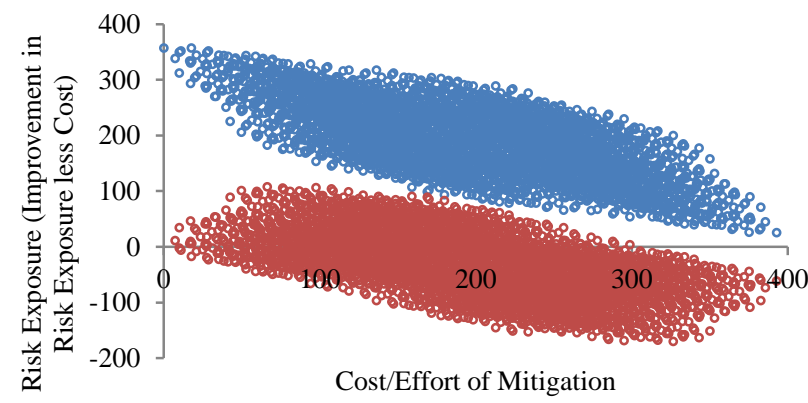

- Risk Exposure $\quad$ Improvement in Risk Exposure less Cost

Fig. 3. Cost and benefit analysis of various combinations of mitigation strategies.

It is also important to differentiate between the optimal and inefficient combinations of strategies. Depending on risk tolerance of the stakeholder, specific levels of risk exposure can be achieved through implementing cost-effective mitigation strategies as shown in Fig. 4. For each level of risk exposure, there are a number of possible combinations of strategies, however, there is a unique cost-efficient combination represented by the lowest value.
The model can also be used to segregate risk mitigation strategies on the basis of controllability. It might be difficult to monitor certain mitigation strategies if these are not directly implemented by the stakeholder. 'Using correct quality programs' and 'selecting the right quality material' are examples of such strategies that may not be easily monitored by the stakeholder. Therefore, we explored evaluating other combinations of strategies after setting the states of these two strategies as 'No'. As the two strategies have been eliminated from consideration, there are a total of 1024 combinations for further analysis. Combination of strategies implemented at a cost of 66.22 units results in the maximum net improvement in risk exposure of 108.24 units as shown in Fig. 5. Corresponding combination of strategies is shown in Table III.

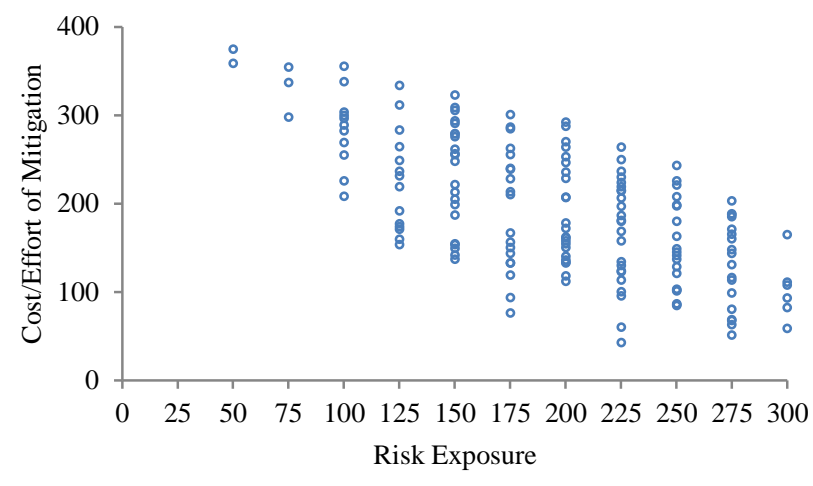

Fig. 4. Optimal combination of strategies for specific level of risk exposure.

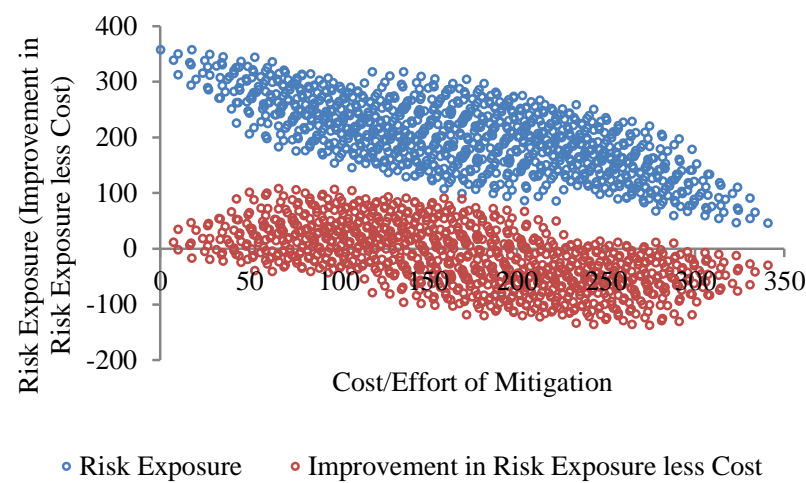

Fig. 5. Cost and benefit analysis of various combinations of mitigation strategies (after prioritizing strategies)

TABLE III. OPTIMAL COMBINATION OF STRATEGIES

\begin{tabular}{ll}
\hline Mitigation Strategy & Implement \\
\hline Effective maintenance & No \\
Visibility of demand to vendor & No \\
Proper company culture & No \\
Communication tools & Yes \\
Selecting the right quality material & No \\
Supplier assessment & No \\
Using correct quality programs & No \\
Training & No \\
Mass customization & Yes \\
Good contact with customer & Yes \\
Implementing the best technology & No \\
As per prevailing market conditions & No \\
\hline
\end{tabular}




\section{Managerial Implications}

This technique can help managers appreciate the impact of key risk triggers on associated risks and evaluate cost-effective mitigation strategies in accordance with their risk tolerance. The proposed method not only helps in identifying key risk factors and assessing risk exposure of a network comprising interacting risk factors, triggers and mitigation strategies but also presents a unique concept of evaluating different risk mitigation strategies through demonstrating cost and benefit analysis. One of the main merits of this tool relates to differentiating optimal combination of strategies from other inefficient combinations. Managers can take informed decisions taking into account the interdependent nature of risks and mitigation strategies.

\section{CONCLUSION}

Existing research in the field of SCRM has not fully explored risk evaluation stage of the risk management process. Specifically, the costs and benefits associated with various combinations of risk mitigation strategies have never been investigated. We have introduced a new modelling approach of determining cost-effective combinations of mitigation strategies taking into account the impact of these strategies across the risk triggers and risk factors. We illustrated our approach through simulating an existing case study and demonstrated its efficacy through conducting cost and benefit analysis. BBN based modelling helped capturing the involved uncertainty and the complexity associated with eliciting a large number of conditional probabilities was tackled through incorporating NoisyOR function within the model.

The proposed approach is an important contribution in terms of introducing a new concept of evaluating risk mitigation strategies. The results clearly provided an insight into realizing the importance of adopting such an approach as implementation of mitigation strategies without performing a rigorous analysis would lead to inefficient outcomes. The process can also be used to select an optimal combination of strategies against a target level of risk exposure. The presented technique will help researchers and practitioners in developing and using efficient models of mitigating supply chain risks respectively.

Though the technique has been illustrated through simulating an existing case study, nonetheless, it needs testing in real case studies in order to appreciate the associated challenges. Furthermore, in case of a huge network with many potential strategies, it might not be feasible to conduct cost and benefit analysis of all combinations of control strategies because of computational complexity. However, it will still be possible to evaluate the optimal combination through treating the clusters of risk triggers and interconnected risk factors as independent.

\section{APPENDIX A. CONDITIONAL PROBABILITY VALUES}

\begin{tabular}{|c|c|c|c|c|c|c|c|c|c|c|}
\hline \multicolumn{11}{|c|}{$P\left(T_{i}=\right.$ True $\left.\mid M_{i}\right)$} \\
\hline M1 & M2 & M3 & M4 & M5 & T1 & T2 & T3 & T4 & T5 & T6 \\
\hline $\mathrm{Y}$ & & & & & 0.1 & & & & & \\
\hline $\mathrm{N}$ & & & & & 0.75 & & & & & \\
\hline & $\mathrm{Y}$ & & & & & 0.05 & & & & \\
\hline & $\mathrm{N}$ & & & & & 0.25 & & & & \\
\hline & & $\mathrm{Y}$ & & & & & $1 e-05$ & & & \\
\hline & & $\mathrm{N}$ & & & & & 0.01 & & & \\
\hline & & & $\mathrm{Y}$ & & & & & 0.001 & & \\
\hline & & & $\mathrm{N}$ & & & & & 0.5 & & \\
\hline & & & & Y & & & & & 0.01 & 0.05 \\
\hline & & & & $\mathrm{N}$ & & & & & & 0.75 \\
\hline
\end{tabular}

\begin{tabular}{cccccc}
\hline M6 & M7 & M8 & T7 & T8 & T9 \\
\hline Y & & & 0.01 & & \\
N & & & 0.25 & & \\
& Y & & & 0.04 & \\
& N & & & 0.75 & 0.05 \\
& & Y & & & 0.5 \\
\hline
\end{tabular}

\begin{tabular}{cccccccc}
\hline M9 & M10 & M11 & M12 & T10 & T11 & T12 & T13 \\
\hline Y & & & 0.1 & & & \\
$\mathrm{~N}$ & & & 0.99 & & & \\
& $\mathrm{Y}$ & & & 0.1 & & \\
& $\mathrm{~N}$ & $\mathrm{Y}$ & & & 0.99 & 0.001 & \\
& $\mathrm{~N}$ & & & & 0.75 & 0.0001 \\
& & $\mathrm{Y}$ & & & 0.5 \\
\hline
\end{tabular}




\begin{tabular}{|c|c|c|c|c|c|c|c|}
\hline \multicolumn{8}{|c|}{$P\left(R_{i} \mid T_{i}=\right.$ True $)$} \\
\hline R1 & T1 & $\mathbf{T} 2$ & T3 & $\mathbf{T} 4$ & T5 & T6 & $\begin{array}{c}\text { Leak } \\
\text { Factor }\end{array}$ \\
\hline $\mathrm{T}$ & 0.9 & 0.9 & 0.8 & 0.85 & 0.99 & 0.75 & 0.01 \\
\hline \multirow[t]{7}{*}{$\mathrm{F}$} & 0.1 & 0.1 & 0.2 & 0.15 & 0.01 & 0.25 & 0.99 \\
\hline & $\mathbf{R 2}$ & T4 & T7 & T8 & T9 & $\begin{array}{c}\text { Leak } \\
\text { Factor }\end{array}$ & \\
\hline & $\mathrm{T}$ & 0.95 & 0.99 & 0.95 & 0.75 & 0.05 & \\
\hline & $\mathrm{F}$ & 0.05 & 0.01 & 0.05 & 0.25 & 0.95 & \\
\hline & $\mathbf{R 3}$ & T10 & T11 & T12 & T13 & $\begin{array}{c}\text { Leak } \\
\text { Factor }\end{array}$ & \\
\hline & $\mathrm{T}$ & 0.99 & 0.65 & 0.8 & 0.8 & 0.05 & \\
\hline & $\mathrm{F}$ & 0.01 & 0.35 & 0.2 & 0.2 & 0.95 & \\
\hline
\end{tabular}

\section{APPENDIX B. LOSS VALUES OF RISK TRIGGERS}

\begin{tabular}{ll}
\hline Risk Trigger & Loss \\
\hline Machine breakdown & 77 \\
Non-availability of raw material & 44 \\
Labour problems & 55 \\
Improperly trained workers & 44 \\
Natural calamity at vendor's place & 1 \\
Failure to communicate & 44 \\
Low quality material used at vendor's facilities & 22 \\
Improper process at the vendor's end & 44 \\
Insufficient use of quality tools & 44 \\
No clear market perception & 99 \\
Poor after-service network & 33 \\
Not using the latest technology & 77 \\
High product cost & 33 \\
\hline
\end{tabular}

\section{APPENDIX C. COST OF Mitigation STRATEGIES}

\begin{tabular}{ll}
\hline Mitigation Strategy & Cost \\
\hline Effective maintenance & 11 \\
Visibility of demand to vendor & 11 \\
Proper company culture & 22 \\
Communication tools & 22 \\
Selecting the right quality material & 11 \\
Supplier assessment & 33 \\
Using correct quality programs & 55 \\
Training & 66 \\
Mass customization & 33 \\
Good contact with customer & 11 \\
Implementing the best technology & 77 \\
As per prevailing market conditions & 44 \\
\hline
\end{tabular}

\section{REFERENCES}

[1] Khan, O. and Burnes, B., Risk and supply chain management: creating a research agenda. International Journal of Logistics Management, 2007. 18(2): pp. 197-216.

[2] White, D., Application of systems thinking to risk management: a review of the literature. Management Decision, 1995. 33(10): pp. 35-45.

[3] Christopher, M. and Lee, H., Mitigating supply chain risk through improved confidence. International Journal of Physical Distribution \& Logistics Management, 2004. 34(5): pp. 388-396.

[4] Sodhi, M.S. and Tang, C.S., Managing supply chain risk, International Series in Operations Research and Mangement Science 172. Vol. 172. 2012: New York : Springer.
[5] Gaudenzi, B. and Borghesi, A., Managing risks in the supply chain using the AHP method. International Journal of Logistics Management, 2006 17(1): pp. 114-136.

[6] Sigurdsson, J.H., Walls, L.A., and Quigley, J.L., Bayesian belief nets for managing expert judgement and modelling reliability. Quality and Reliability Engineering International, 2001. 17(3): pp. 181-190.

[7] Fenton, N.E., Neil, M., and Caballero, J.G., Using Ranked Nodes to Model Qualitative Judgments in Bayesian Networks. IEEE Transactions on Knowledge and Data Engineering, 2007. 19(10): pp. 1420-1432.

[8] Lockamy, A., Benchmarking supplier risks using Bayesian networks. Benchmarking: An International Journal, 2011. 18(3): pp. 409-427. 
[9] Dogan, I. and Aydin, N., Combining Bayesian Networks and Total Cost of Ownership method for supplier selection analysis. Computers and Industrial Engineering, 2011. 61(4): pp. 1072-1085.

[10] Lockamy, A. and McCormack, K., Modeling supplier risks using Bayesian networks. Industrial Management \& Data Systems, 2012. 112(2): pp. 313-333.

[11] Harland, C., Brenchley, R., and Walker, H., Risk in supply networks. Journal of Purchasing and Supply Management, 2003. 9(2): pp. 51-62.

[12] Knight, F.H., Risk, Uncertainty and Profit. 1921: Houghton Mifflin, Boston, MA.

[13] Jüttner, U., Peck, H., and Christopher, M., Supply chain risk management: outlining an agenda for future research. International Journal of Logistics Research and Applications, 2003. 6(4): pp. 197-210.

[14] Christopher, M. and Peck, H., Building the Resilient Supply Chain. International Journal of Logistics Management, 2004. 15(2): pp. 1-14.

[15] Breuer, C., Siestrup, G., Haasis, H.-D., and Wildebrand, H., Collaborative risk management in sensitive logistics nodes. Team Performance Management, 2013. 19(7): pp. 331-351.

[16] Ermoliev, Y.M., Ermolieva, T.Y., MacDonald, G.J., Norkin, V.I., et al., A system approach to management of catastrophic risks. European Journal of Operational Research, 2000. 122(2): pp. 452-460.

[17] Lee, C.K.M., Yeung, Y.C., and Hong, Z., An integrated framework for outsourcing risk management. Industrial Management \& Data Systems, 2012. 112(4): pp. 541-558.

[18] Durowoju, O.A., Chan, H.K., and Wang, X., Entropy assessment of supply chain disruption. Journal of Manufacturing Technology Management, 2012. 23(8): pp. 998-1014.

[19] Wilson, M.C., The impact of transportation disruptions on supply chain performance. Transportation Research Part E: Logistics and Transportation Review, 2007. 43(4): pp. 295-320.

[20] Wu, T., Blackhurst, J., and O'grady, P., Methodology for supply chain disruption analysis. International Journal of Production Research, 2007. 45(7): pp. 1665-1682.

[21] Hopp, W., Iravani, S.R., and Liu, Z., Mitigating the Impact of Disruptions in Supply Chains, in Supply Chain Disruptions, Gurnani, H., Mehrotra, A., and Ray, S., Editors. 2012, Springer London. p. 21-49.

[22] Richey, J.R.G., The supply chain crisis and disaster pyramid: A theoretical framework for understanding preparedness and recovery. International Journal of Physical Distribution \& Logistics Management, 2009. 39(7): pp. 619-628.

[23] Kumar, S. and Havey, T., Before and after disaster strikes: A relief supply chain decision support framework. International Journal of Production Economics, 2013. 145(2): pp. 613-629.

[24] Perry, M., Natural disaster management planning: A study of logistics managers responding to the tsunami. International Journal of Physical Distribution \& Logistics Management, 2007. 37(5): pp. 409-433.

[25] Wieland, A., Selecting the right supply chain based on risks. Journal of Manufacturing Technology Management, 2013. 24(5): pp. 652-668.

[26] Soni, G. and Kodali, R., A decision framework for assessment of risk associated with global supply chain. Journal of Modelling in Management, 2013. 8(1): pp. 25-53.

[27] Ravindran, A.R., Ufuk Bilsel, R., Wadhwa, V., and Yang, T., Risk adjusted multicriteria supplier selection models with applications. International Journal of Production Research, 2009. 48(2): pp. 405-424
[28] Goh, M., Lim, J.Y.S., and Meng, F., A stochastic model for risk management in global supply chain networks. European Journal of Operational Research, 2007. 182(1): pp. 164-173.

[29] Guillén, G., Mele, F.D., Bagajewicz, M.J., Espuña, A., et al., Multiobjective supply chain design under uncertainty. Chemical Engineering Science, 2005. 60(6): pp. 1535-1553.

[30] Sodhi, M.S., Managing demand risk in tactical supply chain planning for a global consumer electronics company. Production and Operations Management, 2005. 14(1): pp. 69-79.

[31] Tang, C. and Tomlin, B., The power of flexibility for mitigating supply chain risks. International Journal of Production Economics, 2008 116(1): pp. 12-27

[32] Johnson, M.E., Learning from Toys: Lessons in managing supply chain risk from the Toy industry. California Management Review, 2001. 43(3): pp. 106-124.

[33] Zsidisin, G.A., Ellram, L.M., Carter, J.R., and Cavinato, J.L., An analysis of supply risk assessment techniques. International Journal of Physical Distribution \& Logistics Management, 2004. 34(5): pp. 397 413

[34] Blackhurst , J., Craighead, C.W., Elkins, D., and Handfield, R.B., An empirically derived agenda of critical research issues for managing supply-chain disruptions. International Journal of Production Research, 2005. 43(19): pp. 4067-4081.

[35] Kleindorfer, P.R. and Saad, G.H., Managing Disruption Risks in Supply Chains. Production and Operations Management, 2005. 14(1): pp. 5368

[36] Sinha, P.R., Whitman, L.E., and Malzahn, D., Methodology to mitigate supplier risk in an aerospace supply chain. Supply Chain Management: An International Journal, 2004. 9(2): pp. 154-168.

[37] Tummala, R. and Schoenherr, T., Assessing and managing risks using the Supply Chain Risk Management Process (SCRMP). Supply Chain Management: An International Journal, 2011. 16(6): pp. 474-483.

[38] Badurdeen, F., Shuaib, M., Wijekoon, K., Brown, A., et al., Quantitative modeling and analysis of supply chain risks using Bayesian theory. Journal of Manufacturing Technology Management, 2014. 25(5): pp 631-654.

[39] Kelangath, S., Das, P.K., Quigley, J., and Hirdaris, S.E., Risk analysis of damaged ships - a data-driven Bayesian approach. Ships and Offshore Structures, 2011. 7(3): pp. 333-347.

[40] Qazi, A., Quigley, J., and Dickson, A. Supply Chain Risk Management: Systematic literature review and a conceptual framework for capturing interdependencies between risks. in 5th International Conference on Industrial Engineering and Operations Management. 2015. Dubai, UAE.

[41] Bolt, J. and van der Gaag, L., An Empirical Study of the Use of the Noisy-Or Model in a Real-Life Bayesian Network, in Information Processing and Management of Uncertainty in Knowledge-Based Systems. Theory and Methods, Hüllermeier, E., Kruse, R., and Hoffmann, F., Editors. 2010, Springer Berlin Heidelberg. p. 11-20.

[42] Jensen, F.V. and Nielsen, T.D., Bayesian networks and decision graphs 2007: Springer-Verlag, New York.

[43] The Decision Systems Laboratory, GeNIe and SMILE. [accessed on 22 March, 2015]; Available from: http://genie.sis.pitt.edu/about.html. 